\title{
Elegy in which I am not whisked away
}

I feel a distance from every corner in the world. I offer a woman my coat, and she laughs, and she laughs. Is it even raining? My old eyes bloom against the blue light of the window. Though every night I am not alone I am alone during the day, and it disarranges me. It dissects me. I have stopped looking for the word for it in books, or incense, or even the huge tongue of moon on my floor. In its mouth I see only the shadow of last month, how I held the dead cat in my arms, how much heavier he was dead than alive, how in the limp light of his body there was nothing more than the limp light. Maybe this is how winter always feels, slick and bloated, a sachet of sweat. I slid my finger down his throat to feel a breath. Outside, my boots sank into the snow with only that, that not feeling anything but the sinking. On the empty street, we made a sound that has no name. And nothing closed its paw around me that night. It was just heavy. I wrapped him in my coat and gave the cold flag of him to someone else. There were no wild crows, blacking out the sky. There was the gloss of a room, becoming something darker. That night, I held my weight over the whole mouth of him, felt his warm slack tongue and did not think, then, that the body was brutal to be so, to keep crimped behind its teeth this pocket of heat. There was nothing hot about what later I gave my body to, how I pulled up my skirt and the boy said, It's like that, and I said, Yes, and stubbed myself out against the cold files of his arms. His mouth made these sounds, and if I was not thirsty then I was dry when he left.

This is the answer to the sweating throat of winter. A scorch of water for tea. A dead moth floating to the surface. I burn my finger skimming him out, drop his body into the sink, let the clear wilt of water take this too. 